\title{
The Past, Present and Future of Learning Analytics
}

\author{
Anna Sigridur Islind \\ Reykjavik University, \\ Department of Computer \\ Science, School of \\ Technology, Iceland. \\ islind@ru.is
}

\author{
María Óskarsdóttir \\ Reykjavik University, \\ Department of Computer \\ Science, School of \\ Technology, Iceland. \\ mariaoskars@,ru.is
}

\author{
Sara Willermark \\ University West, School of \\ Business, Economics \& \\ IT, Department of Media \\ \& Design, Sweden. \\ sara.willermark@hv.se
}

\author{
Galina Deeva \\ KU Leuven, Research \\ Centre for Information \\ Systems Engineering, \\ Belgium. \\ galina.deeva@,kuleuven.be
}

\section{Learning Analytics}

The research interest in learning analytics and educational data mining is rapidly growing. These two closely related research fields are focused on the learner to understand the learning process [1]. In particular, educational data mining (EDM) is concerned with developing methods for exploring the unique and growing large-scale data that can be derived from educational settings, and using those methods for an indepth understanding of students, and the settings in which they learn [2, 3]. In comparison, learning analytics focuses on analyzing teaching and learning behaviors through learning management systems (or learning platforms) through already established datadriven approaches [4]. The interests include to shed light on the data types required to improve learning in different levels of education, and how data can be used to better understand and improve the educational environment. Learning analytics discusses different approaches for data analysis by opening up the box of how machine learning techniques can discover relevant factors that improve teaching and learning outcomes [5]. The area extends to network analysis [6], and to novel approaches where educational data can give new insights. However, learning analytics is expanding to include qualitative research on teaching and learning, using qualitative data to support these processes [7]. The field therefore not merely encompasses big data and grand projects but also uses small data with a high level of details that can support teaching or learning in various ways.

\section{Present trends in IS research}

Learning analytics includes various types of research that relies on digital traces from learning platforms, which outline a common source of data in learning analytics. These digital traces can be widely used to predict learning behavior, which can be complemented by including research where the learning behaviours are explained through qualitative methods, where both teachers and learners perspectives are included. As a result of that, the minitrack on learning analytics at HICSS 2021 welcomed papers that took the point of departure from the teacher side, from a student perspective, or from the intersection between the teachers' and the students' practices. In addition to that, the papers could take on challenges and benefits for management, operations, practice or research and could be drawn from the aforementioned modern, broad definition of learning analytics.

More specifically, we welcomed papers related to learning analytics and datafication in educational settings alongside papers reflected on changes in learning platforms, teaching and learning practices, student profiling, and use of third-party applications to support education. The track therefore includes everything from small apps to large learning platforms and infrastructures in educational contexts that generate data that could be analyzed and used to impact educational outcomes. We also welcomed a dialog on continuous education, and the impact of technologies on workplace learning and continuous education strategies. We see the future of learning analytics as an area of interest that is based on both qualitative and quantitative methods, and on machine learning approaches.

The four accepted contributions in the minitrack on HICSS 2021 reflect different aspects of learning analytics in relation to intelligent tutoring systems (ITS) [8], virtual reality [9], student privacy [10] and informal learning [11]. More specifically, the topic of ITS is tackled through exploring the challenges mathematics teachers encounter when they implement a digital mathematics textbook with an integrated ITS. The paper presents a formative intervention conducted in a twoyear project with 16 secondary school teachers. The method was based on activity theory and required the teachers to collaborate with researchers in analyzing their work activity when the new teaching tool was introduced. The findings of the paper, which show that an ITS created systemic contradictions for the teachers, contribute to a better understanding of teachers' responses to a technology aimed at automating teaching processes [8]. The paper on virtual reality is aimed at exploring the factors that affect the use of virtual reality 
online learning systems (VROLS). It is based on the theory of cost-benefit perspective and incorporates the perceived value and the flow theories proposes an integrated research model elaborating on why people opt for VROLS services. The findings, which are based on online questionnaires and structural equation modeling, suggest that both perceived value and flow experience are important roles in users' use of VROLS services [9]. The third accepted paper focuses on exploring to what extent privacy is valuable for learning. The research addresses findings from a survey of over 500 full-time higher education instructors. Data indicate that faculty believe that privacy is important to intellectual behaviors and learning [10]. The fourth and final accepted paper proposes a framework that adds the contextual elements of task design, tools and technologies, and datasets to established learning analytics processes. The proposed framework was developed as a design science research artifact, working with teachers of English at two Swedish secondary schools. The results highlight the importance of valid task design for generating relevant insights and provide a basis for simplifying and automating in-situ learning analytics that can be used by teachers in their everyday work.

\section{Future trends in Learning Analytics}

Learning analytics have made a substantial and lasting impact on research and practice in learning and teaching. Although inclusion of educational research has been acknowledged as being fundamental [12], the majority of published papers are descriptive in nature without use of theory [13]. Integrating the two would elevate the field. Learning theory can instruct research in learning analytics, by guiding the selection of research questions to investigate, in formulating hypotheses, designing experiments, and advising the design and evaluation of tools and interventions [14]. There is also a need for examining learning over longer periods of time, using larger sample sizes and more heterogeneous samples of students to generalise results and get a fuller picture [15].

In the last months we have witnessed a rapid shift towards blended and distance learning, involving an almost overnight adoption of the necessary technology. The consequences of this evolution are still unknown, such as the effects on learning and teaching strategies in e.g. (partially) online settings. As a result, we foresee that a substantial part of learning analytics research in the near future will be focussed on the impact of the COVID-19 pandemic on education. Only time will tell what the true impact of this evolution is, what the real benefits and serious pitfalls are, as well as the difficulties we must overcome.

\section{References}

[1] Siemens, G. and P. Long, 2011, Penetrating the fog: Analytics in learning and education. Educause review, 46(5): pp. 30.

[2] Van Barneveld, A., K.E. Arnold, and J.P. Campbell, 2012, Analytics in higher education: Establishing a common language. Educause learning initiative. 1(1): pp. 1-11.

[3] Daniel, B., 2015, Big Data and analytics in higher education: Opportunities and challenges. British journal of educational technology. 46(5): (pp. 904-920).

[4] Islind, A. S., Norström, L., Hult, H. V., and Olsson, S. R. 2020. Socio-Technical Interplay in a Two-Sided Market: The Case of Learning Platforms. In Digital Transformation and Human Behavior, (pp. 33-53). Springer, Cham.

[5] Deeva, G., De Smedt, J., De Koninck, P., and De Weerdt, J., 2017, September. Dropout prediction in MOOCs: a comparison between process and sequence mining. In International Conference on Business Process Management, (pp. 243-255). Springer, Cham.

[6] Óskarsdóttir, M., and Bravo, C. 2020. Multilayer Network Analysis for Improved Credit Risk Prediction. arXiv preprint arXiv:2010.09559.

[7] Willermark, S. 2018. Technological pedagogical and content knowledge: A review of empirical studies published from 2011 to 2016. Journal of Educational Computing Research, 56(3), 315-343.

[8] Utterberg Modén, M., Tallvid, M, Lundin, J and Lindström, B. 2021. Intelligent Tutoring Systems: Why Teachers Abandoned a Technology Aimed at Automating Teaching Processes. Proceedings of the 54th Hawaii International Conference on System Sciences.

[9] Wang, Y-T, Lin K-Y and Huang, T. 2021. An analysis of learners' intentions toward virtual reality online learning systems: a case study in Taiwan. Proceedings of the 54th Hawaii International Conference on System Sciences.

[10] Jones, K., VanScoy, A., Bright, K. and Harding, A. 2021. Do They Even Care? Measuring Instructor Value of Student Privacy in the Context of Learning Analytics. Proceedings of the 54th Hawaii International Conference on System Sciences.

[11] Risk, A., 2021. A Framework for Informal Learning Analytics - Evidence from the Literacy Domain. Proceedings of the 54th Hawaii International Conference on System Sciences.

[12] Gašević, D., Dawson, S., \& Siemens, G. 2015. Let's not forget: Learning analytics are about learning. TechTrends, 59(1), 64-71.

[13] Viberg, O., Hatakka, M., Bälter, O., \& Mavroudi, A. 2018. The current landscape of learning analytics in higher education. Computers in Human Behavior, 89, 98-110.

[14] J. Wong, M. Baars, B. B. de Koning, T. van der Zee, D. Davis, M. Khalil, G.-J. Houben, and F. Paas, 2019, in Utilizing learning analytics to support study success, (pp. 325). Springer, Cham.

[15] Leitner, P., Khalil, M., \& Ebner, M. 2017. Learning analytics in higher education - a literature review. In Learning analytics: Fundaments, applications, and trends (pp. 1-23). Springer, Cham. 